illustrations and objects to this exhibition. Among these were illustrations of Arabian surgical instruments from early fourteenth century manuscripts ; examples of the medical and other works of Maimonides, the Hispano-Jewish philosopher and physician of the twelfth century; replicas of the earliest MSS. of the life of Andres Laguna, physician to Charles $V$ and Pope Julian III; Roman, medieval, Hindu and modern surgical instruments; historical objects such as Egyptian artificial eyes, anatomical models, and a special section devoted to the evolution of

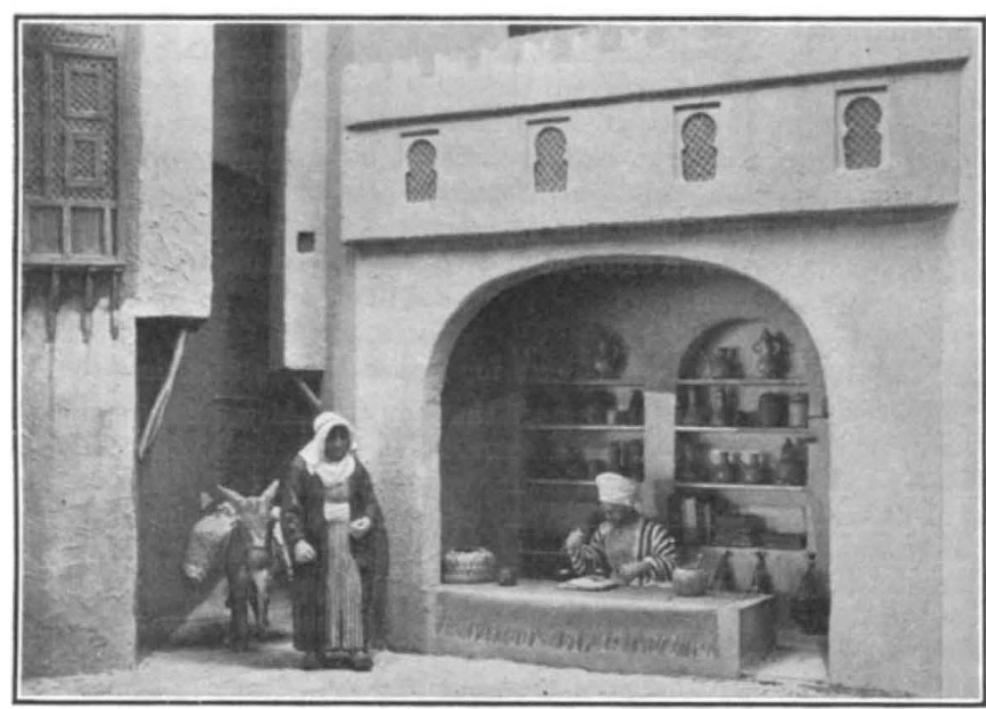

FTG. 1. Diorama of a Hispano-Moresque apothecary's shop.

Copyright: The Wellcome Historical Medical Museum (The Wellcome Foundation, Ltd.).

road carpeting of a lighter hue. In the future it is possible that on all the busy roads lights on the vehicles may be unnecessary and the approaching driver will see the oncoming vehicle, not as a couple of spots of dazzling light on a black background, but as a dark silhouette against an adequately illuminated road. The improvements in vehicles, especially the introduction of four-wheeled brakes, has greatly facilitated free movement of traffic on the streets, and the compulsory test for every new driver has worked admirably, about 12 per cent being rejected. It is recognised that certain drivers are 'accident prone'. and these must be eliminated as soon as possible. Science may help us to keep the demonstrably unfit off the road, but until science, and not a human driver, assumes control of the vehicle, occasional breakdowns in traffic control are bound to occur.

\title{
Fewer Accidents in Well-Lighted Streets
}

According to the Electrician of September 20 the first accident statistics for the section of the highway between Versailles and Ville d'Avray have been published. This road has recently been lighted with sodium vapour lamps (discharge tube lamps), and the statistics show a reduction of 74 per cent in the number of accidents, none of which

spectacles. Part of the Museum's exhibit comprised interesting dioramas including Nicholas Monardes of Seville (1512-88) depicted working in his private museum of curiosities ; a historic incident connected with the discovery of cinchona bark as a remedy for malaria (1630); a thirteenth century apothecary's shop in Cordova (Fig. 1); and an interior view of the hospital of Santa Cruz at Toledo as it appeared in the sixteenth century.

\section{Scientific Control of Road Traffic}

ON September 10, at the British Association meeting in Norwich, Mr. A. T. V. Robinson opened a joint discussion in Sections $G$ (Engineering) and $J$ (Psychology) on the control of road traffic. He said that the question is far wider than merely the prevention of accidents ; that it is how to move with a minimum of delay, discomfort and damage a system consisting of heterogeneous units of passengers and goods travelling for industry and pleasure in all directions. Of the year's total of 7,000 fatal accidents, about 2 per cent were due to the defects of the vehicle, somewhat less than 2 per cent to defects of the road, and the remaining 96 per cent were due to the personal equation. Engineers study either the roads or the vehicles, and the psychologist studies the drivers and pedestrians. Mr. Robinson emphasised the importance of the colourisation of the 'carpeting' of the road, and said we ought to endeavour to get was of a serious nature. Local authorities should consider these figures, which prove that lives can be saved by the proper lighting of rural roads.

\section{Closing Down of Private Electric Generating Stations}

Several of the large factories in Great Britain have been considering whether it is an economical proposition to close down their generating stations and take their electric supply from the Grid. As the facilities offered by the public supply increase and the price diminishes, the advantages in its favour are rapidly increasing. Messrs. Lever Bros., of Port Sunlight, who were well known to have one of the largest and most efficient private plants in the country, have now entered into an arrangement whereby their power station becomes associated with the Grid, and will, under the direction of the Central Board, be operated by the Birkenhead Station. The load taken will be 40 million units a year, which is equivalent to the needs of a large town. The consumption of Birkenhead itself is 41 million units and the consumption of towns such as Oxford, Peterborough and Plymouth are less than 40 million units. Port Sunlight, the centre of the great soap and similar products manufacturing business, has an area of about 2,000 acres, and several other firms have established factories on the estate. The demand is likely to increase in the future. Among other large firms which have recently changed over from a private to 